\title{
Serum Cystatin C as a Useful Marker for Evaluation of Renal Function at Birth: A Pilot Study
}

\author{
Mariko Sawada ${ }^{*}$, Kazutoshi Ueda ${ }^{1}$, Kanako Yoshizaki ${ }^{1}$, Satoko Tokumasu ${ }^{1}$, Masamichi Kubota ${ }^{1}$, \\ Akihito Takahashi ${ }^{1}$, Masaaki Hasegawa ${ }^{2}$ and Shinichi Watabe ${ }^{1}$
}

${ }^{1}$ Department of Pediatrics, Kurashiki Central Hospital, Japan

${ }^{2}$ Department of Obstetrics and Gynecology, Kurashiki Central Hospital, Japan

*Corresponding author: Mariko Sawada, Department of Pediatrics, Kurashiki Central Hospital, 1-1-1 Miwa, Kurashiki, Okayama, Japan, Tel: +81-86-422-0210; E-mail: mariko-sawada@hotmail.co.jp

Received date: January 21, 2018; Accepted date: February 02, 2019; Published date: February 05, 2019

Citation: Sawada M, Ueda K, Yoshizaki K, Tokumasu S, Kubota M, et al. (2019) Serum Cystatin C as a Useful Marker for Evaluation of Renal Function at Birth: a Pilot Study. J Clin Exp Nephrol Vol.4 No.1: 01. DOI: 10.21767/2472-5056.100073

Copyright: @ 2019 Sawada M, et al. This is an open-access article distributed under the terms of the Creative Commons Attribution License, which permits unrestricted use, distribution, and reproduction in any medium, provided the original author and source are credited.

\section{Abstract}

Background: Serum creatinine $(\mathrm{SCr})$ is widely used to test renal function. $\mathrm{SCr}$ at birth is strongly affected by maternal $\mathrm{SCr}$ and does not reflect the renal function of the neonate. Serum cystatin $\mathrm{C}$ (CysC) has been used as an indicator of glomerular filtration rate in adults and children. However, CysC has not been widely used to evaluate kidney function in neonates until now.

Methods: The renal function of neonates admitted to our neonatal intensive care unit was evaluated by analyzing cord blood CysC levels at birth using a latex immunoturbidimetric assay.

Results: The cord blood CysC and $\mathrm{SCr}$ of ten neonates was measured at birth. The CysC levels of four patients without impaired renal function were between 1.26 and $1.53 \mathrm{mg} / \mathrm{L}$. The CysC level in one case whose mother was diagnosed with chronic kidney disease was not elevated $(1.60 \mathrm{mg} / \mathrm{L})$, although the patient's SCr level was elevated $(2.25 \mathrm{mg} / \mathrm{dL})$. The CysC levels of three patients with acute kidney injury due to asphyxia were slightly higher (1.78 to $2.17 \mathrm{mg} / \mathrm{L}$ ) than those in patients without acute kidney disease. The CysC levels of two patients diagnosed with renal failure were substantially higher $(4.09$ and $7.07 \mathrm{mg} / \mathrm{L})$ than those of patients without renal failure.

Conclusion: CysC shows potential as a useful marker to evaluate the kidney function of neonates at birth, as CysC is not affected by maternal CysC.

Keywords: Neonate; Premature baby; Serum creatinine; Serum bystatin $\mathrm{C}$; Glomerular filtration rate

\section{Introduction}

Early detection of renal function in neonatal intensive care unit (NICU) is vital, because NICU mortality rates are strongly associated with renal failure and acute kidney injury (AKI). Glomerular filtration rate (GFR) is the most common indicator of kidney function [1]; the gold standard for measuring GFR is inulin clearance. However, the measurement of GFR is difficult in clinical practice, especially in neonates. Serum creatinine $(\mathrm{SCr})$ is the most commonly used factor for the estimation of GFR, including in neonates. However, $\mathrm{SCr}$ at birth is strongly affected by maternal $\mathrm{SCr}$, because $\mathrm{Cr}$ is transported across the placenta in a bidirectional manner. Tubular back filtration of $\mathrm{Cr}$ is the cause of a further serious limitation of its use as a marker of renal function in premature neonates. Therefore, $\mathrm{SCr}$ does not reflect the renal function of neonates during the first a few days of life. Furthermore, it is difficult to evaluate neonatal renal function, especially in premature babies. Premature babies are exposed to various kinds of medications, many of which are excreted through the urine. During the neonatal period, major developmental changes in renal function occur, with renal function changing daily after birth [2]. $\mathrm{SCr}$ is therefore probably not a useful marker of neonatal GFR. Serum cystatin C (CysC) has come to be used for stage classification of chronic kidney disease (CKD) and as an indicator of GFR in adults and children. Additionally, because CysC does not cross the placenta, cord blood and serum CysC reflects renal function in neonates. Unfortunately, CysC is currently not widely used to evaluate kidney function in neonates.

In this study, we evaluated cord blood CysC in Japanese neonates to evaluate their kidney function at birth.

\section{Methods}

Study population and design: A single-center retrospective cohort study was performed at the Kurashiki Central Hospital (Kurashiki, Japan) from November 2016 to January 2018. This pilot study was performed on patients who underwent cord blood CysC measurements at birth. We evaluated cord blood CysC and $\mathrm{SCr}$ levels in the patients, as well as the $\mathrm{SCr}$ levels of their mothers. The patients were divided into four groups based on their and their mothers' renal function, as follows: 
Group A: Patients and their mothers had no renal function impairment.

Group B: Patients had no renal impairment, but their mothers had CKD.

Group C: Patients were diagnosed with AKI not requiring dialysis without maternal renal function impairment.

Group D: Patients were diagnosed with renal failure requiring dialysis without maternal renal function impairment.

\section{Clinical data collection}

Clinical data from neonates and their mothers were collected using a retrospective chart review. AKI was defined based on the neonatal modified KDIGO classification [3]. CKD was defined based on the K/DOQI definition and classification [4].

\section{Measurement of cord blood CysC and $\mathrm{SCr}$ and maternal SCr levels}

We measured the levels of CysC in umbilical venous blood at birth, and the levels of $\mathrm{SCr}$ at birth. Maternal SCr levels were measured on the day of delivery. CysC concentrations in cord blood and serum samples were analyzed using a latex immunoturbidimetric assay (N-assay LA Cystatin C, NITTOBO MEDICAL CO., Japan) and an automatic analyzer (LABOSPECT-008, Hitachi High-Technologies, Japan). $\mathrm{SCr}$ concentrations were analyzed using an enzyme assay (creatinase-sarcosine oxidase-peroxidase method) (L-Type Creatinine M, FUJIFILM Wako Pure Chemical CO., Japan) and an automatic analyzer (LABOSPECT-008, Hitachi High-Technologies, Japan) (Figures $\mathbf{1}$ and 2).

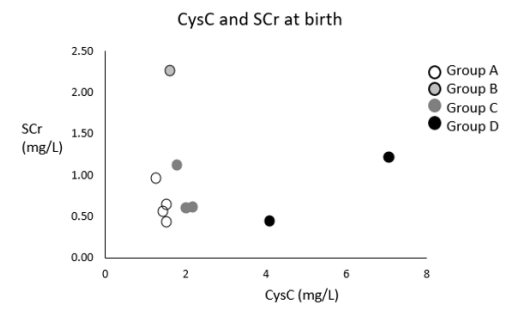

Figure 1: Cord blood CysC and $\mathrm{SCr}$ at birth.

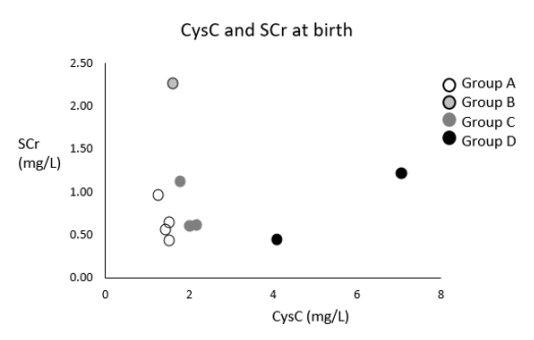

Figure 2: Cord blood CysC and $\mathrm{SCr}$ at birth.

\section{Ethical approval}

The study protocol was approved by the Institutional Review Board of the Kurashiki Central Hospital (No. 3605; January, 2019) and complied with the Helsinki declaration and its later amendments or comparable ethical standards.

\section{Results}

The cord blood CysC of ten neonates was measured at birth. Table 1 presents the clinical characteristics of these ten neonates. The patients had a gestational age of between 31 and 41 weeks, and a birth weight of between 859 and 3,390 g (Table 1).

Group A included four neonates; neither the neonates nor their mothers presented with impaired renal function at birth. The CysC levels of patients in Group A were between 1.26 and $1.53 \mathrm{mg} / \mathrm{L}$. Case 4 died of congenital heart disease on day of life (DOL) 25. However, the other three patients were discharged from NICU with normal kidney functions, including one premature baby.

Group B included a single case where the patient's mother was diagnosed with CKD due to autosomal dominant polycystic kidney disease (ADPKD). The CysC level of the patient in Group B was not elevated $(1.60 \mathrm{mg} / \mathrm{L})$, although the patient's $\mathrm{SCr}$ level was elevated $(2.25 \mathrm{mg} / \mathrm{dL})$. The post-natal ultrasound [DOL 1] showed no renal cysts and normal bilateral kidneys. She was discharged with normal kidney function.

Group $C$ included three cases diagnosed with AKI due to neonatal severe asphyxia. The CysC levels in Group $C$ were a slightly higher (1.78-2.17 mg/L) than those in Groups A and B. In case 7 and 8 , the patients were treated using hypothermic therapy. Group C maternal kidney function was within normal ranges. Cord blood CysC was slightly elevated $(1.78-2.17 \mathrm{mg} / \mathrm{L})$ at birth. They presented with elevated $\mathrm{SCr}$ at DOL 2-4 and oliguria at DOL 1 , and they were diagnosed with AKI. Fortunately, their renal function was fully recovered at NICU discharge.

Group D included two cases diagnosed with renal failure after birth. Although both patients presented with normal SCr levels at birth, the CysC levels of the Group D patients were markedly higher $(4.09$ and $7.07 \mathrm{mg} / \mathrm{L})$ than those in other groups. Case 9 was diagnosed with renal oligohydramnios and pulmonary hypoplasia before birth. The post-natal ultrasound [DOL 1] was consistent with a diagnosis of congenital solitary kidney and left hypoplastic kidney. Her left kidney presented with hyperechogenicity and the length of the major axis was $14 \mathrm{~mm}$. She suffered from oliguria and displayed a urine output (UOP) of $<0.5 \mathrm{~mL} / \mathrm{kg} / \mathrm{h}$. Her parents were informed of the severe clinical conditions of their child; the data, including measured CysC levels, indicated a poor prognosis, and the patient was treated with palliative care. The child died of renal failure at DOL 12 . In case 10, the mother had been treated with angiotensin II receptor blocker (ARB) during pregnancy to prevent hypertension, because the mother did not notice her pregnancy due to high obesity (body mass index: 49). Although there were improvements in the hypertension of the mother, maternal $\mathrm{SCr}$ 
was found to be elevated around the delivery date. The postnatal ultrasound [DOL 1] showed highly echogenic kidneys, and diastolic renal flow was not detected. The patient's respiratory and circulatory condition was stable, but he continued to suffer from anuria and hyperkalemia despite conservative treatment strategies including glucose-insulin therapy, fluid therapy, and diuretics. On DOL 4, continuous renal replacement therapy
(CRRT) was performed on the patient to prevent renal failure (hyperkalemia, hyperuricemia, and volume overload). On DOL 7, his renal function recovered partially $(\mathrm{SCr} 0.36 \mathrm{mg} / \mathrm{dL}$, CysC 3.30 $\mathrm{mg} / \mathrm{L}$ ), and his urine output increased greatly (UOP 3.0 $\mathrm{mL} / \mathrm{kg} / \mathrm{h}$ ). Therefore, CRRT was discontinued in the patient. On DOL 19, he was discharged form NICU with acute kidney disease. At present, he is being treated for CKD.

Table 1: Clinical characteristics of neonates.

\begin{tabular}{|c|c|c|c|c|c|c|c|c|c|c|c|c|c|}
\hline \multirow{2}{*}{ Case } & \multirow{2}{*}{ Group } & \multirow{2}{*}{ Sex } & \multirow{2}{*}{$\begin{array}{l}\text { Gestational } \\
\text { age (weeks) }\end{array}$} & \multirow{2}{*}{$\begin{array}{l}\text { Birth } \\
\text { weight } \\
\text { (g) }\end{array}$} & \multirow[t]{2}{*}{$\begin{array}{l}\text { Underlying } \\
\text { disease }\end{array}$} & \multirow[t]{2}{*}{$\begin{array}{l}\text { Maternal } \\
\text { disease }\end{array}$} & \multirow[t]{2}{*}{$\begin{array}{r}\text { CysC } \\
(\mathrm{mg} / \mathrm{ml})\end{array}$} & \multirow[t]{2}{*}{$\begin{array}{c}\mathrm{SCr} \\
(\mathrm{mg} / \mathrm{ml})\end{array}$} & \multirow{2}{*}{$\begin{array}{l}\text { Maternal } \\
\text { SCr } \\
(\mathrm{mg} / \mathrm{ml})\end{array}$} & \multirow[t]{2}{*}{ Outcome } & \multirow[t]{2}{*}{$\begin{array}{l}\text { Requiring } \\
\text { dialysis }\end{array}$} & \multicolumn{2}{|c|}{$\begin{array}{l}\text { Renal outcome at } \\
\text { discharge }\end{array}$} \\
\hline & & & & & & & & & & & & $\begin{array}{l}\mathrm{sCr} \\
(\mathrm{mg} / \mathrm{ml})\end{array}$ & $\begin{array}{r}\text { CysC } \\
(\mathrm{mg} / \mathrm{ml})\end{array}$ \\
\hline 1 & $A$ & $M$ & 29.4 & 1.276 & - & - & 1.26 & 0.96 & 0.74 & Alive & - & 0.26 & 1.29 \\
\hline 2 & A & $M$ & 27.7 & 859 & - & - & 1.44 & 0.55 & 0.59 & Alive & - & 0.3 & 1.53 \\
\hline 3 & $A$ & $\mathrm{~F}$ & 34 & 1.398 & - & - & 1.51 & 0.33 & 0.33 & Alive & - & 0.25 & 1.43 \\
\hline 4 & $A$ & $\mathrm{~F}$ & 41.1 & 2.614 & CoA. AVSD & - & 1.53 & 0.64 & 0.52 & $\begin{array}{l}\text { Dead } \\
24)\end{array}$ & - & - & - \\
\hline 5 & $B$ & $\mathrm{~F}$ & 35.3 & 2.245 & - & $\begin{array}{l}\text { CKD due } \\
\text { to ADPKD }\end{array}$ & 1.6 & 2.25 & 2.18 & Alive & - & 0.36 & 1.64 \\
\hline 6 & $\mathrm{C}$ & M & 35 & 1.476 & $\begin{array}{l}\text { AKI due to } \\
\text { severe } \\
\text { asphyxia }\end{array}$ & - & 1.78 & 1.11 & 0.56 & Alive & - & 0.3 & 1.37 \\
\hline 7 & $\mathrm{C}$ & M & 38.9 & 3.39 & $\begin{array}{l}\text { AKI due to } \\
\text { severe } \\
\text { asphyxia }\end{array}$ & - & 2.01 & 0.6 & 0.51 & Alive & - & 0,45 & 1.79 \\
\hline 8 & $\mathrm{C}$ & $\mathrm{F}$ & 38.6 & 2.928 & $\begin{array}{l}\text { AKI due to } \\
\text { severe } \\
\text { asphyxia }\end{array}$ & - & 2.17 & 0.61 & 0.59 & Alive & - & 0.46 & 1.41 \\
\hline 9 & 0 & $\mathrm{~F}$ & 31.3 & 1.38 & $\begin{array}{l}\text { Sole kidney } \\
\text { and } \\
\text { hypoplastic } \\
\text { kidney }\end{array}$ & - & 4.09 & 0.44 & 0.45 & $\begin{array}{l}\text { Dead (DOL } \\
12)\end{array}$ & + & & - \\
\hline 10 & $D$ & $M$ & 38 & 3.168 & $\begin{array}{l}\text { AKD due to } \\
\text { ARB }\end{array}$ & $\begin{array}{l}\text { Severe } \\
\text { HDP }\end{array}$ & 7.07 & 1.21 & 1 & Alive & + & 1.41 & 3.3 \\
\hline
\end{tabular}

SCr: Serum Creatinine; CysC: Cystatin C; DOL: Day of life; AKD: Acute Kidney Disease; ARB: Angiotensin II Receptor Blocker; HDP: Hypersensitive Disorder of Pregnancy; CKD: Chronic Kidney Diseases; ARPKD: Autosomal Dominant Polycystic Kidney Disease; AKI: Acute Kidney Injury; CoA: Coarctation of the Aorta; AVSD: Atrioventicular Ceptalm Defect

\section{Discussion}

There are several markers for evaluating GFR; of them, CysC has been the well-studied in recent years. CysC is a lowmolecular weight protein produced at a constant rate in all human cells with a nucleus. CysC is filtered freely through glomeruli and almost completely reabsorbed and metabolized by the proximal tubular cells [5-7]. Serum CysC has been described as a promising biomarker of renal function, and several meta-analyses of recent studies favored CysC over $\mathrm{SCr}$ for the detection of impaired GFR in almost all age groups $[7,8]$, including neonates [9].

On the other hand, there have been limited studies investigating $\mathrm{CysC}$ in neonates [5,9-13]. Unlike creatinine, CysC does not cross the placenta and is not affected by maternal renal function [5,6]. Furthermore, CysC is not affected by sex, age, or muscle mass. Therefore, its level closely reflects neonatal kidney function $[5,6,9]$. Postnatal CysC is closely related to postconceptional age (PCA) [12]. Serum CysC in small for gestational age (SGA) was found to be slightly higher than that in apropriate for gestational age (AGA) $(p=0.087)$ [5]. Other papers have reported that serum $\mathrm{Cys} C$ in the first 3 postnatal days might be affected by maternal factors such as maternal serum CysC levels or body mass, as well as the maturation of infants. Cys $C$ levels tend to decrease as the PCA increases during the first 30 postnatal days [12]. The $\mathrm{Cys} \mathrm{C} / \mathrm{Cr}$ ratio shows potential as an effective renal marker in pediatric patients, including neonates [14]. Little is known regarding the metabolism of CysC in preterm infants and during the postnatal maturation of kidney function [15].

There are only a few studies reporting the reference values of serum and cord blood CysC in neonates. Allegaert et al. analyzed CysC levels in newborns [16]. The CysC reference interval (RI) was shown to be independent of gestational age, birth weight, 
and maternal $\mathrm{Cr}$, according to previous reports. Elmas et al. reported the RIs of serum CysC in preterm neonates (1.34 \pm 0.1 $\mathrm{mg} / \mathrm{L}$ in $28-29$ weeks gestation, $1.28 \pm 0.2 \mathrm{mg} / \mathrm{L}$ in $30-32$ weeks gestation, and $1.24 \pm 0.2 \mathrm{mg} / \mathrm{L}$ in 33-34 weeks gestation) [17]. De Novo et al. reported the RIs in term neonates as $1.70 \pm 0.26$ $\mathrm{mg} / \mathrm{L}$ [18]. Parvex et al. reported the median CysC levels in term babies as $2.02 \mathrm{mg} / \mathrm{L}$ [6]. Dorum et al. reported the Rls in term neonates as $1.21 \pm 0.31 \mathrm{mg} / \mathrm{L}$ [19]. Very few studies have analyzed the serum CysC RIs in preterm neonates. Finney et al. reported these RIs as $1.48 \mathrm{mg} / \mathrm{L}$ at 24-28 weeks gestation and $1.65 \mathrm{mg} / \mathrm{L}$ at 29-36 weeks gestation [11]. Bariciak et al. determined the RIs as $1.63 \mathrm{mg} / \mathrm{L}$ at 24-28 weeks gestation and $1.60 \mathrm{mg} / \mathrm{L}$ at 28-32 weeks gestation at DOL 3 [10]. In our cases, the CysC levels of the patients in group A-who displayed no renal impairment-were $1.26-1.53 \mathrm{mg} / \mathrm{L}$. Our data were consistent with those of previous studies in terms of RIs in neonates. Differences in analysis methods of Cys $\mathrm{C}$ must be considered when referring to previous papers. Not many reports have investigated CysC Rls at birth; therefore, further studies into RIs in neonates are needed to use it as a marker of renal function.

In neonates with congenital anomalies of kidney and urinary tracts (CAKUT), several studies have reported that cord blood or fetal serum CysC levels were a good marker to evaluate their kidney function [6,20-22]. Parvex et al. found that the median cord blood CysC levels in the survivor groups with CAKUT were 1.97 [21] and 1.98 [6] mg/L. Tomotaki et al. reported that cord blood CysC levels were significantly higher in the non-survivor group with CAKUT than in the survivor group (4.48 vs. 1.96 $\mathrm{mg} / \mathrm{dL}$ ) [20]. These three papers concluded that the median cord blood CysC level in the survivor groups was $1.97 \mathrm{mg} / \mathrm{L}[6,20,21]$. Muller et al. reported that the prenatal serum CysC levels in fatal fetuses with bilateral hypoplasia and cystic dysplasia were significantly higher than those in controls $(2.60$ and 2.92 vs. 1.43-1.62 $\mathrm{mg} / \mathrm{L}$ ) [22]. In this study, in case 9 from Group D, the measured cord blood CysC level was $4.09 \mathrm{mg} / \mathrm{L}$, and she later died of renal failure. According to previous reports, case 9 could be predicted as a fatal outcome. In addition to clinical courses and $\mathrm{SCr}$ measurement, CysC measurement could help in the early diagnosis of renal dysfunction and be vital for decisionmaking. Although higher CysC levels are associated with increased mortality, we should not use only CysC levels as a predictor of early mortality in neonates. On the other hand, the early management of CAKUT could decrease mortality and improve long-term renal function. Cord blood and fetal serum CysC levels might be a useful marker for the severity of renal dysfunction in neonates and fetuses with CAKUT $[6,21]$.

AKI is associated with poor outcomes as an independent risk factor [23]. Early detection of AKI would contribute to efforts improve neonatal outcome in NICU. Serum CysC has been proposed as a filtration marker for the early detection of AKI. A meta-analysis reported that the cutoff value of CysC for predicting AKI was $0.96 \mathrm{mg} / \mathrm{L}$ [95\% Cl, 0.95-0.97] in adults [24]. Several previous studies have reported the relationship between cord blood and serum CysC and neonatal AKI. Hadzimuratovic et al. reported that serum CysC levels were significantly higher in severely asphyxiated infants compared to those in mild-tomoderately asphyxiated newborns; they further reported that higher serum CysC levels were associated with neurodevelopmental deficits [25]. Treiber et al. reported that umbilical cord CysC levels were significantly higher in infants exposed to perinatal asphyxia compared to controls ( $2.12 \pm 0.53$ vs. $1.39 \pm 0.21 \mathrm{mg} / \mathrm{L})$, and that the cutoff values for AKI prediction were $1.67 \mathrm{mg} / \mathrm{L}$ (sensitivity $84.0 \%$, specificity $90.0 \%$ ) or $1.69 \mathrm{mg} / \mathrm{L}$ (sensitivity $82.0 \%$, specificity $94.0 \%$ ) [26]. Sarafidis et al. reported that CysC levels at birth were significantly higher in asphyxiated neonates compared to those in healthy ones ( 2.86 vs. $2.23 \mathrm{mg} / \mathrm{L}$ ). They further reported the cutoff value of CysC at birth for predicting AKI was $2.87 \mathrm{mg} / \mathrm{dL}$ (sensitivity $66.7 \%$, specificity 92.3\%) [27]. Elmas et al. investigated premature infants with respiratory distress syndrome, and reported that serum CysC levels in the AKI group were significantly higher than those in the control group $(1.14 \pm 0.1$ vs. $1.49 \pm 0.09 \mathrm{mg} / \mathrm{L}$ at DOL 3 [17]. Kasamatsu et al. reported that serum CysC levels at birth could predict urine volume during the first $24 \mathrm{~h}$ of life. These findings indicate that serum Cys $C$ could be a useful biomarker for assessing early neonatal children, because the measurement of urine volume is essential to identifying oliguria, which is an early predictor of high mortality or adverse prognoses in critically ill patients [28]. On the other hand, Maruniak-Chudek et al. reported that serum CysC was not a useful marker of renal function in neonates with sepsis [29]. In our study, group C patients, who had AKI due to asphyxia, showed slightly elevated CysC levels at birth compared to those in group A patients, who showed normal kidney function (1.26-1.53 vs. $1.78-2.17 \mathrm{mg} / \mathrm{dL})$. Based on these findings, CysC at birth is a potential indicator of mild-tomoderate renal function. In neonates, it is not clear whether serum CysC is a good predictor of AKI development.

In conclusion, we reported ten neonates who were evaluated in terms of their kidney function using cord blood CysC. Cord blood CysC levels might be a good marker for the severity of renal dysfunction at birth without an invasive procedure. Previous reports have already found that CysC is a highly sensitive, accurate, and reliable marker for GFR; it has been shown to be sensitive to even mild or moderate changes in GFR. Although small concentrations of CysC may cross the placenta, it is currently the most widely available endogenous marker for GFR in newborns that are independent of maternal renal function. Accurately evaluating renal function at birth could reduce mortality rates and improve renal outcomes in neonates. Further studies on the relationship between kidney dysfunction and serum and cord blood CysC at birth are required.

\section{Conflicts of Interest}

The authors declare that they have no conflict of interest.

\section{Informed Consent}

Identifying information of patients should not be published unless the information is essential for scientific purposes and the patient (or parent or guardian) gives informed consent for publication. 


\section{References}

1. Filler G, Browne R, Seikaly MG (2003) Glomerular filtration rate as a putative 'surrogate end-point' for renal transplant clinical trials in children. Pediatr Transplant 7: 18-24.

2. Kearns GL, Abdel-Rahman SM, Alander SW, Blowey DL, Leeder JS, et al. (2003) Developmental pharmacology-drug disposition, action, and therapy in infants and children. New Engl J Med 349: 1157-1167.

3. Jetton JG, Askenazi DJ (2014) Acute kidney injury in the neonate. Clin Perinatol 41: 487-502.

4. Levey AS, Eckardt KU, Tsukamoto Y, Levin A, Coresh J, et al. (2005) Definition and classification of chronic kidney disease: a position statement from Kidney Disease: Improving Global Outcomes (KDIGO). Kidney Int 67: 2089-2100.

5. Treiber M, Balon BP, Gorenjak M (2015) A new serum cystatin C formula for estimating glomerular filtration rate in newborns. Pediatr Nephrol 30: 1297-1305.

6. Parvex P, Combescure C, Rodriguez M, Girardin E (2012) Is Cystatin $\mathrm{C}$ a promising marker of renal function, at birth, in neonates prenatally diagnosed with congenital kidney anomalies? Europ Dial Transplant Assoc 27: 3477-3482.

7. Filler G, Bökenkamp A, Hofmann W, Le Bricon T, Martínez-Brú C, et al. (2005) Cystatin $C$ as a marker of GFR-history, indications, and future research. Clin Biochem 38: 1-8.

8. Roos JF, Doust J, Tett SE, Kirkpatrick CM (2007) Diagnostic accuracy of cystatin $C$ compared to serum creatinine for the estimation of renal dysfunction in adults and children-a metaanalysis. Clin Biochem 40: 383-391.

9. Armangil D, Yurdakök M, Canpolat FE, Korkmaz A, Yiğit Ş, et al. (2008) Determination of reference values for plasma cystatin $C$ and comparison with creatinine in premature infants. Pediatr Nephrol 23: 2081-2083.

10. Bariciak E, Yasin A, Harrold J, Walker M, Lepage N, et al. (2011) Preliminary reference intervals for cystatin $C$ and beta-trace protein in preterm and term neonates. Clin Biochem 44: 11561159.

11. Finney H, Newman DJ, Thakkar H, Fell JM, Price CP (2000) Reference ranges for plasma cystatin $\mathrm{C}$ and creatinine measurements in premature infants, neonates, and older children. Arch Dis Child 82: 71-75.

12. Lee JH, Hahn WH, Ahn J, Chang JY, Bae CW (2013) Serum cystatin C during 30 postnatal days is dependent on the postconceptional age in neonates. Pediatr Nephrol 28:1073-8.

13. Treiber M, Balon BP, Gorenjak M (2014) Cystatin C versus creatinine as a marker of glomerular filtration rate in the newborn. Wiener klinische Wochenschrift. 2006; 118 Suppl 2:6670.

14. Hahn WH, Bae CW (2014) Reference intervals of serum cystatin C/ creatinine ratio of 30 postnatal days in neonates. Pediatr Nephrol. 29: 311-314.
15. Filler G, Lepage $N$ (2013) Cystatin C adaptation in the first month of life. Pediatr Nephrol 28: 991-994.

16. Allegaert K, Mekahli D, van den Anker J (2015) Cystatin C in newborns: a promising renal biomarker in search for standardization and validation. J Matern Fetal Neonatal Med; 28: 1833-1838.

17. Elmas AT, Tabel Y, Elmas ÖN (2013) Serum cystatin C predicts acute kidney injury in preterm neonates with respiratory distress syndrome. Pediatr Nephrol 28: 477-484.

18. Novo AC, Sadeck LD, Okay TS, Leone CR (2011) Longitudinal study of Cystatin C in healthy term newborns. Clinics. 66: 217-220.

19. Dorum S, Silfeler I, Dorum BA, Silfeler DB, Canbak Y, et al. (2012) Reference values of serum cystatin- $C$ for full-term and preterm neonates in Istanbul. Indian J Pediatr 79: 1037-1042.

20. Tomotaki S, Toyoshima K, Shimokaze T, Shibasaki J, Nagafuchi H (2017) Association between cord blood cystatin C levels and early mortality of neonates with congenital abnormalities of the kidney and urinary tract: a single-center, retrospective cohort study. Pediatr Nephrol 32: 2089-2095.

21. Parvex P, Combescure C, Rodriguez M, Birraux J, Girardin E (2014) Evaluation and predictive factors of renal function progression using cystatin $\mathrm{C}$ and creatinine in neonates born with CAKUT. Clin Nephrol.; 81:338-344.

22. Muller F, Dreux S, Audibert F, Chabaud JJ, Rousseau T, et al. (2004) Fetal serum ss2-microglobulin and cystatin $C$ in the prediction of post-natal renal function in bilateral hypoplasia and hyperechogenic enlarged kidneys. Prenat Diag 24: 327-332.

23. Koralkar R, Ambalavanan N, Levitan EB, McGwin G, Goldstein S, et al. (2011) Acute kidney injury reduces survival in very low birth weight infants. Pediatr Res 69: 354-358.

24. Zhang Z, Lu B, Sheng X, Jin N (2011) Cystatin C in prediction of acute kidney injury: a systemic review and meta-analysis. Am J Kidney Dis 58: 356-365.

25. Hadzimuratovic E, Skrablin S, Hadzimuratovic A, Dinarevic SM (2014) Postasphyxial renal injury in newborns as a prognostic factor of neurological outcome. J Matern Fetal Neonatal Med 27: 407-410.

26. Treiber M, Gorenjak M, Pecovnik Balon B (2014) Serum cystatin-C as a marker of acute kidney injury in the newborn after perinatal hypoxia/asphyxia. Ther Apher Dial 18: 57-67.

27. Sarafidis K, Tsepkentzi E, Agakidou E, Diamanti E, Taparkou A (2012) Serum and urine acute kidney injury biomarkers in asphyxiated neonates. Pediatr Nephrol 27: 1575-1582.

28. Macedo E, Malhotra R, Bouchard J, Wynn SK, Mehta RL (2011) Oliguria is an early predictor of higher mortality in critically ill patients. Kidney Int 80: 760-767.

29. Maruniak-Chudek I, Owsianka-Podleśny T, Wróblewska J, JadamusNiebrój D (2012) Is serum cystatin C a better marker of kidney function than serum creatinine in septic newborns? Postepy Hig Med Dosw 66: 175-180. 